\title{
LEJOS DEL PARAÍSO. INMIGRANTES COLOMBIANOS EN LA ESPAÑA DE HOY
}

\section{FAR FROM THE PARADISE. COLOMBIAN IMMIGRANTS IN SPAIN OF TODAY}

\author{
Balvina Rodríguez Benavides \\ Universidad de León. España/Spain \\ balvinar@hotmail.com
}

Recibido/Received: 01/02/2011

Aceptado/Accepted: 15/06/2011

\section{RESUMEN}

En este artículo se reflexiona sobre la importancia del fenómeno de las migraciones y su incidencia en la sociedad española actual. Ahondando en el conocimiento de los sujetos que emigran, sus razones, el marco social que las produce, los imaginarios que despierta en relación con el mejoramiento de sus vidas; aspectos que se estudian desde "documentos personales" como las "historias de vida". Por medio de éstas, podemos acceder al presente de los individuos y estudiar como ellos han ido construyendo una memoria migratoria que les permite tener conciencia temporal de un antes y un después de emprender dicho proceso; a la vez que explicar y dar sentido a su propia realidad como inmigrantes.

\section{PALABRAS CLAVE}

Emigración colombiana, inmigración en España, documentos personales, historias de vida, memoria migratoria.

\section{SUMARIO}

1. Introducción. 2. Las historias de vida como instrumento para el estudio del fenómeno migratorio. 3. Historias de vida de los inmigrantes colombianos en España. 4. A modo de conclusión. Bibliografía.

\begin{abstract}
The article is a reflection about migration phenomenon and this impact in the actual society in Spain to study depth of the details in the knowledge about emigrate, subjects reasons and social framework that produce, the imaginaries awake the relation with the improvement this life aspects studies since "personal documents" and "life stories". Through these we can access to the present of the persons and study how they have been built a migratory memory that permit have temporal conscience about the before and after to start this process; explain and give sense for their own reality how immigrants.
\end{abstract}

\section{KEYWORDS}

Colombian emigration, Spain immigration, personal documents, life stories, migratory memory.

\section{CONTENTS}

1. Introduction. 2. The life histories how instrument to study the migratory phenomenon. 3. Life histories of the Colombian immigrants in Spain. 4. As a way of conclusion. References. 


\section{INTRODUCCIÓN}

En nuestro mundo contemporáneo, caracterizado por crecientes procesos de globalización, los movimientos migratorios - con todas las implicaciones sociales que conllevan- se han convertido en un fenómeno de investigación y reflexión de primer orden para los diversos ámbitos de las ciencias sociales. Sin duda, uno de los aspectos que este fenómeno entra a cuestionar es el de la identidad social y cultural de las sociedades receptoras, en particular el apego de estas sociedades a sus raíces y costumbres tradicionales (Blanco, 2008: 267-288). Lo que desemboca, en muchos casos a modo de respuesta de estas sociedades receptoras, en nacionalismos extremos que superponen el "yo" y lo "nuestro" como un referente de exclusión y de conflicto permanente frente al "otro" (Bernárdez Rodal, 2007).

Es por cuestiones como éstas, de trascendental importancia para dimensionar el fenómeno migratorio hacia los llamados países del primer mundo, que este fenómeno no debe entenderse como un hecho aislado, sino como un proceso propio de la sociedad global, lo que lleva a atenderse y comprenderse desde el mayor número de escenarios explicativos posibles. Los investigadores sociales no pueden seguir dando preferencia y privilegiando la óptica cuantitativa, "acosados" por unas administraciones nacionales para quienes todo se reduce a cuántos llegan, cuántos hay, cuánto tiempo se quedan y cuántos se van (Checa, 2002).

\section{LAS HISTORIAS DE VIDA COMO INSTRUMENTO PARA EL ESTUDIO DEL FENÓMENO MIGRATORIO}

Las historias de vida resultan un método viable y de gran riqueza para abordar distintos aspectos del actual fenómeno migratorio (Marsal, 1972; Binebine, 2000; Ramírez, 1996; Torres, 1995; Sánchez Molina, 2006). No sólo aportando nuevos cuerpos de evidencia sociohistórica -las fuentes orales- sino también privilegiando una aproximación cualitativa desde procesos de conocimiento socio antropológico.

Las historias de vida propician una práctica historiográfica asociada al hecho de recabar y analizar testimonios personales a modo de relatos, en los que el sujeto da sentido a su proyecto de vida. El investigador social, a partir de la reordenación de la cadena y el bagaje de acontecimientos, vivencias y aprendizajes de un sujeto y/o de una colectividad, posibilita la compresión, y da significación individual y social a esas múltiples experiencias, a modo de una trama o argumento que conlleva una dimensión temporal, adscrita a un espacio histórico y geográfico determinado. De esta manera, el investigador social logra determinar razones y consecuencias; entrelazando la acción individual en un tejido social y cultural determinado.

Todo relato de vida es en sí, una búsqueda de sentido y justificación que confirma o cuestiona la trayectoria de las acciones pasadas, presentes y futuras de un individuo o un grupo de individuos, Los individuos construyen su identidad personal, social y cultural, en función de "quiénes son" y "por qué son" así. Un autorretrato social e histórico que no es sólo recuerdo del pasado, sino "memoria migratoria" que adquiere plena justificación en el presente. Por ello, narrar sobre lo que se "ha sido" o se "ha hecho" es una manera de establecer una estrategia identitaria en base a la construcción de esa "memoria migratoria" de identidad personal, que se inscribe también en una "memoria migratoria" de identidad colectiva, y que en tanto que memoria, es apropiación de lo vivido y da sentido a sus condiciones presentes y futuras de vida. En este proceso, las historias de vida se ocupan de 
poner en contraste el punto de vista subjetivo (lo que el individuo piensa de él y cree que piensan los otros) con el sujeto social clasificado como "inmigrante" en una sociedad de acogida ajustada a leyes y protocolos de actuación plenamente definidos. "Una motivación fundamental de la investigación basada en el documento personal es permitir que se oigan voces que son normalmente silenciadas: las víctimas de lo que Becker llama una "jerarquía de la credibilidad" pueden llegar a otros con sus propias palabras, traspasando lentamente esa "cierta ceguera". (Plummer, 1989:93). De este modo, se hace "visible" -a los ojos de la sociedad y la política- lo "invisible"; lo que tradicionalmente se considera parte de lo privado. En otras palabras, se pretende permanecer abierto y atento a la emergencia de nuevos tipos de sujetos individuales y colectivos, enfrentados a la búsqueda de nuevas certezas e interdependencias.

Existe una cierta tradición consolidada de la metodología de las historias de vida en la investigación social. Por citar algunos casos relevantes, por ejemplo tenemos el trabajo del sociólogo español emigrado a la Argentina, Juan Francisco Marsal que siguiendo los planteamientos de la escuela de Chicago publicó un estudio autobiográfico: Hacer la América. Autobiografía de un emigrante. Obra en la que narró, en primera persona, su experiencia como inmigrante catalán en la Argentina (Marsal, 1972) al modo en que Thomas y Znaniecki hicieran en el muy conocido estudio: El Campesino Polaco en Europa y en América (Thomas y Znaniecki, 2006)

Otro caso reseñable es, sin duda, la obra: Los Hijos de Sánchez, del investigador norteamericano Oscar Lewis, en la que se aborda -a modo de novela- la historia de cinco familias Mexicanas (Lewis, 2004) La interpretación que hace de la vida urbana y de los sectores populares que sobreviven en la pobreza, de la familia como unidad de análisis y de observación, así como el despliegue de herramientas y técnicas de investigación, hacen de este texto un referente fundamental del investigador dedicado a las historias de vida.

Las historias de vida se basan en una metodología en la que la entrevista en profundidad es una herramienta esencial. Por este motivo en la investigación que llevo a cabo, y que constituye mi tesis doctoral, sobre los inmigrantes colombianos en España he realizado numerosas entrevistas en profundidad a distintos inmigrantes, tanto hombres como mujeres. Inicialmente, si bien se establece en la entrevista un patrón inducido por preguntas que incitan a que el entrevistado nos relate los hechos de manera cronológica, ese patrón va sufriendo modificaciones a medida de que me son dadas las respuestas. Así, en algún momento, nos detenemos para detallar aspectos sobre la información que nos suministra, insistiendo en el hecho de que el entrevistado sea capaz de ofrecer mayor profundidad. No obstante, el objetivo principal de la entrevista es generar la producción de una historia significativa del sujeto en relación con su experiencia migratoria. Y, sobre todo, saber de qué manera y en base a qué recursos o herramientas interpretativas, el sujeto ha interiorizado y ha explicado esta experiencia migratoria, construyendo una memoria del proceso. Es decir, un "autorretrato narrativo" por medio del cual el sujeto desea ser conocido y valorado.

\section{HISTORIAS DE VIDA DE LOS INMIGRANTES COLOMBIANOS EN ESPAÑA}

En los procesos de migración se pueden "leer" en las relaciones con el "otro", que las identidades son más el producto del señalamiento de la diferencia y la exclusión que signos de una unidad identitaria que podíamos denominar natural. En este sentido, los cambios 
identitarios se expresan de manera contundente, cuando los inmigrantes (solos o con familia) hacen referencia a sus vivencias. Los inmigrantes dan cuenta de la importante influencia que las prácticas cotidianas privadas y las relaciones en redes familiares y afectivas tienen en la construcción de su identidad nacional y cultural. Así, algunos elementos que expresan las diferencias culturales y los cambios identitarios, en pro de una adaptación a los nuevos códigos de la sociedad de acogida, como por ejemplo, la alimentación, posturas idiomáticas, nuevos roles sociales de la mujer y el hombre, la educación de los hijos, creencias y manifestaciones religiosas, etc. Y ello se lleva a cabo a pesar de que los inmigrantes latinoamericanos en España son considerados como un colectivo con "menores problemas de integración" en comparación con otros inmigrantes de Asía o África, especialmente los de confesión musulmana (Calderón, 2008). De esta manera, los latinoamericanos "serían adaptables" en mayor medida que otro grupo de inmigrantes, por el hecho de poseer un idioma y "compartir" una historia y, hasta cierto modo, unos referentes culturales comunes.

Para plantear esta supuesta "mejor asimilación" de los referentes sociales y culturales de la sociedad española respecto al colectivo inmigrante latinoamericano, se parte de supuestos de carácter "neocolonialista", dado que se da "por supuesto" que la impronta colonial española llevada a cabo durante más de trescientos años en el contexto del continente americano perteneciente al proceso de Conquista y Colonización a partir del llamado "Descubrimiento de América", dejó eficazmente su huella cultural. No obstante, este supuesto neocolonial manejado todavía desde las esferas del planteamiento estatal español ante el fenómeno de la inmigración latinoamericana, y que a su vez ha impregnado los imaginarios sociales españoles, no tiene en cuenta la diversidad cultural del llamado grupo latinoamericano: ni sus referentes indígenas presentes y activos en sus sociedades de origen; ni tampoco los llamados grupos afrolatinoamericanos que también se hayan muy presentes en dichos países condicionando sus realidades. Por el contrario, este supuesto está en función de una lectura "criolla" del mundo americano; es decir, desde una perspectiva eurocentrista que hegemoniza falsamente realidades pluriculturales y plurisociales.

Por último, también hay que recordar, que este referente neocolonial está también presente en el imaginario de los propios inmigrantes latinoamericanos quienes, en muchos casos, pretenden presentarse como grupos nacionales homogéneos desconociendo esas realidades pluriculturales de sus países; y entrando en contradicción con discursos que denominaremos de "carácter regional", en donde toda esa realidad pluricultural y pluriracial sí está muy presente como activadora de su cotidianeidad e identidad frente al propio "otro nacional". Aún así, la comunidad de inmigrantes latinoamericanos no se ha escapado de las "peligrosas manifestaciones xenófobas" que la sociedad actual española ha desarrollado frente a los inmigrantes (García Roca y Lacomba, 2008).

La mayoría de los inmigrantes son conscientes de los nuevos referentes culturales del país de acogida; y aunque pueden no compartirlos, saben que su presencia en el país pasa por su adaptación. Adaptación que comienza por respetar las leyes y costumbres de los nacionales españoles; aunque son reacios, la mayoría de las veces, a que estas leyes y costumbres les hagan cuestionar o perder las suyas. En este sentido, se produce una situación paradójica, marcada por un conflicto de intereses que, en algunos casos, desemboca en un claro rechazo a todo aquello que pueda sonar a integración. En ese sentido, el aislamiento, la vida a modo de pequeños "guetos sociales", forma parte de esta respuesta defensiva que contrariamente va estigmatizando aun más su conducta. En todo caso, la gran mayoría de los inmigrantes pasan en algún momento por crisis de identidad, por el cuestionamiento de sus valores y la 
puesta en duda de sus propias referencias culturales. Es un proceso doloroso que está plagado de mucho subjetivismo y de momentos de grandes dudas existenciales, pudiendo desembocar en respuestas violentas, marginación social; o, por el contrario, asimilación, abandono de una identidad para aspirar a otra.

No obstante, el contexto social y cultural de las sociedades de acogida, caso de la española, hace que los inmigrantes vayan buscando formas de adaptarse al "discurso hegemónico identitario" de los autóctonos, y en el que participan las imágenes que el mismo colectivo de inmigrantes tiene sobre "el español". Todo ello por una incesante necesidad de ser reconocidos e integrados; o, por lo menos, no excluidos. Las viejas narrativas identitarias culturales y nacionales se conjugan de manera dinámica con relación al nuevo contexto, en nuevos valores sociales, creando procesos ambivalentes y contradictorios que los conducen a recrear sus identidades alrededor de "marcar las diferencias" con los "otros"; lo que el sociólogo español Manuel Castells denomina: "identidad defensa" (Castells, 1998). Es decir, una actitud generada por las posiciones-condiciones devaluadas o estigmatizadas que llega a una confrontación de resistencia por parte de los inmigrantes y también por parte de los españoles. Los valores morales aparecen como elementos decisivos en el establecimiento de las diferencias y las nuevas adscripciones identitarias. Veamos un ejemplo de ello. En una pregunta a un inmigrante varón colombiano se establece:

P/ ¿Retomando la conversación anterior, me decías qué era la integración para ti?

R/ ¿Qué es la integración? Para mí la integración es agruparse, tener (largo silencio, no sabe que contestar)... ¿La reintegración me está diciendo? (Confunde los términos). Entrar ante una sociedad y compartir y vivir, para mi forma de pensar, no.

$\mathbf{P} /$ ¿Tú te sientes una persona integrada en la sociedad española?

R/ No.

P/ ¿Por qué?

R/ Porque me siento a ratos discriminado, por racismo, trabajo.

$\mathbf{P} /$ ¿Racismo de qué tipo de piel?

R/ Piel, económico, el habla (Silencio) o trabajo.

P/ ¿Pero tú eres del piel blanca Jairo?

R/ No soy negro, pero es que les notan a uno... el habla: ellos enseguida lo rechazan.

P/ ¿Pero eres español y estás casado?

R/ Pero yo con decirle a esa persona yo soy casado no, pero yo no, yo eso no creo, eso no lo aceptan. Ellos creen que nosotros les estamos haciendo mal aquí, un 50 - $60 \%$ de las personas españolas se sienten mal con los extranjeros.

$\mathbf{P} /$ ¿Tú qué crees que piensan los españoles de los colombianos?

R/ Siempre nos lo han dicho, que somos traficantes, que somos coqueros... (Silencio)... pero no saben de que nosotros producimos...... Si... y los brutos son los que la consumen. Allá se produce y aquí son los que se la consumen... (Silencio). Los países ricos son los que la consumen, en nuestro país no se consume coca como la consumen aquí.... Y como les he discutido, aquí hacen pan y venden pan... ¿cierto? Y el que lo come y se vuelve obeso es porque quiere... consumirlo ¿cierto? En Colombia se produce la coca, no la consumimos porque el capital, la gente no lo consume, y los países que manejan el dinero sucio, son desarrollados que son los que les gusta... y ellos son los que se están matando, nosotros no, allá se produce pero más aquí se consume. 
Como se observa, la construcción de "su identidad" se alimenta de las imágenes que "los españoles" tienen de ellos, y del proceso de asimilación que "los españoles" hacen de esas imágenes. Los discursos que crean los inmigrantes se convierten en una respuesta circunstancial a las realidades adversas, incluso cuando el proceso implica aferrarse a las identidades nacionales de origen, a modo de una muestra de lealtad a su país que reacciona a las condiciones "hostiles" de la sociedad receptora. Las respuestas obtenidas en las entrevistas realizadas tienden a confirmar los "perversos estereotipos peyorativos" contra los de "afuera"; así como los obstáculos para la integración por la precariedad de la relación entre el inmigrante y el país receptor.

P/ ¿Tú qué crees que piensan los españoles de los colombianos?

$\mathbf{R} /$ ehh la mayoría, la mayoría nos tienen en buen concepto, aunque no faltaaaaaaa, no falta el gilipollas por ahí que nos relacione es con la coca, siempre... porque he tenido más que todo en el trabajo "ha que tu eres colombiano joder, entonces tu sabes dónde, donde puedo conseguirme un buen gramo de coca" siempre lo relacionan a uno es con eso.

Si bien es cierto que las reinterpretaciones de la identidad colectiva de los inmigrantes colombianos llevan a la reafirmación de sus diferencias (regionalismos) en una dinámica de resistencia y protección, es importante anotar como estas transformaciones también se producen alrededor del reconocimiento de otros que no parecen ser tan diferentes y con los cuales se identifican:

P/ ¿Y crees que el comportamiento de la gente es estos lugares es acorde al comportamiento de la gente en sus países o que la gente de aquí se hace una idea de cómo son los latinos por lo que ven en los bares?

R/ Ehhh si, lo que pasa es que en los bares latinos, bueno se toma... allí en mi país se bebe muy desenfrenadamente no es como aquí... los españoles van de poteo van a un bar se toman un tinto, van al otro máximo dos o tres copas en un sitio, los latinos no, los latinos se sientan en un lugar y piden una botella, dos, tres y se ponen hasta reventar y ya; pues si hubieran dos personas vale, pero ya cuando hay veinte, treinta, cuarenta formas de pensar y de diferentes regiones y culturas que somos allí también entonces es ahí donde resulta que somos, en el momento de un problema o de lo que sea... en eso si somos muy diferentes a los españoles, ellos por ejemplo chillan pero ellos no se van a las manos o no, los latino no, los latinos se dicen dos o tres palabras y ya dejan de discutir y ... y se encienden a los puños o con lo que tengan.

$\mathbf{P} /$ ¿Tú crees que los españoles piensan que los colombianos son violentos?

R/ Sí.

P/ ¿Por la violencia de Colombia o por qué?

R/ Por la manera de ser de nosotros.

$\mathbf{P} /$ ¿Y cómo es la manera de ser de los colombianos?

R/ Fuertes, fuertes que le hablamos con la verdad y no es más, precisamente esta semana tuve un problema ahí en el trabajo y veníamos con dos españoles, estábamos trabajando: cuatro españoles, dos colombianos y... a mí y ya me estaban poniendo un apodo y no lo acepté.

P/ ¿Qué apodo? 
R/ Pues diciéndome que yo era el que el "papi", que yo era el "papi" (silencio)...y eso porque le dicen al encargado de la obra, que no hace nada que es el "papi", entonces que yo soy el "papi" también, entonces un día en el almuerzo me dijeron siente en el puesto del "papi", "papi"....... Entonces me quieren tocar y una vez me aguanté, hasta cuando se me llenó la taza y ayer les dije: a mí me respetan, si vamos pa' apodos, a apodos nos vamos, pero a mí me respetan y no es más; yo los he respetado, respétenme. Yo no les estoy poniendo apodos, ¿quieren apodos? yo también les pongo apodos (silencio)... trátenme como es y listo. Yo les respeto, ustedes respétenme y no es más.

$\mathbf{P} /$ ¿Y haberles dicho esto, es sinónimo de ser fuerte?

R/ Pararlos sí. Decirles la verdad sí. Es decir hasta aquí y no es más (silencio). Si no les gusta miren a ver, que yo he tenido varios problemas aquí por eso, porque me han querido gritar, me han querido... maltratar y yo no me dejo...porque aquí lo quieren gritar a uno.

P/ ¿Gritar los españoles?

R/ Sí........ ¡uhhhhhhhh!

P/ ¿Los españoles hablan fuerte?

R/ Hablan fuerte, pero cuando uno también les habla fuerte también se callan. Cuando le ven a uno que le habla más fuerte entonces ahí sí se callan.

$\mathbf{P} /$ ¿Pero pueden hablar fuerte porque es su timbre de voz?

$\mathbf{R} /$ ¿Y, y, y por qué se callan cuando uno también les habla duro?

$\mathbf{P} /$ ¿Los colombianos no tienen un timbre de voz fuerte?

$\mathrm{R} /$ Pero... entonces cuando le habla fuerte entonces ahí sí,... ¡ itranca porque tranca!

Como se observa, las relaciones sociales parten de apreciaciones subjetivas y del supuesto derecho que tiene una comunidad de hablar de la otra, sobre todo cuando se concibe que es de manera peyorativa:

$\mathbf{P} /$ ¿Te molesta que los españoles hablen de Colombia?

R/ Sí, sí, porque no tienen por qué hablar, que no hablen mal, (sube la voz) Pero que tampoco... que no hablen mal, por qué nos tienen que criticar como personas malas, si es que nosotros no somos malos...todos no somos malos; porque hay dos o tres que son malos, ¿todos somos malos? No, de ninguna manera.

P/ ¿Pero sus comentarios no tienen por qué ser siempre malos?

R/ Noooooo. A mí me han dicho que las colombianas son muy guapas, muy hermosas, muy simpáticas, que no sé qué; que tráigame una colombiana... Pero eso yo... ¡eso sí me siento contento! O que me digan que en Colombia hay tal fruta y ¡uhyyy! O que tal cosa hay en Colombia que es rico o que me trajeron tal cosa un detalle de Colombia que es rico... Eso sí me llama la atención, eso me agrada. (Silencio) Porque a todo tiro le vayan a decir que son coqueros, que son drogadictos que son esto; que si es que allá no conocemos eso la producimos; pero allá la mayor parte del país no la consume. En Colombia se produce droga pero el país no lo consume, aquí lo consumen los muchachos, los niños. En Colombia no llega un muchacho, usted no puede ver con un pedazo de coca o cinco gramos de coca por qué, porque el niño no tiene el capital para comprar un gramo de coca; aquí un niño con la paga que le dan los padres, compran un gramo de coca (silencio)... ¡eso es así! 
$\mathbf{P} /$ ¿Y tú haces comentarios de España positivos cuando estas compartiendo?

R/ Sí, no hay tanto peligro para la mujer tanto como pa'el hombre en la calle, en nuestro país cuando yo vine, existía mucho peligro. Salir uno solo o salir con dinero o unas zapatillas buenas o algo así, cuando yo vine de Colombia, hoy en día no sé, pero aquí... una vida sana, sana en el momento que uno quiera ser sano. Porque yo quiero ser malo aquí droga existe y uno gana pa` comprar droga, pero el que no gusta de eso no gusta... ¿sí?

Por otra parte, la supuesta "conciencia latinoamericana" se construye en el escenario migratorio -al igual que la identidad nacional- sobre el parámetro de la diferencia. Es decir, la "identidad latinoamericana" surge así de factor compartido por identidades nacionales continentales muy distintas, en su relación con el "otro no latinoamericano". (Larraín, 1996: 121) Esta tendencia nos llevaría a plantear el surgimiento de valiosos procesos de integración social de los colectivos de inmigrantes en España, en la medida en que el establecimiento de dichas relaciones no implica la renuncia a la diferencia sino al reconocimiento del extraño.

Sin embargo esta "emergente identidad" no puede considerarse ingenuamente como garantía del mejoramiento del status de los inmigrantes latinoamericanos en España. Por ejemplo, sin desconocer la aparición de pandillas juveniles (Latin Kings, Ñetas, etc.) formadas por jóvenes latinoamericanos y sus enfrentamientos en las calles de algunas grandes ciudades (Madrid, Barcelona, Valencia, Bilbao). Los medios de comunicación alimentan un contexto hostil de percepción ciudadana, creando sentimientos de desconfianza entre las personas inmigrantes y autóctonas que lleva al rompimiento de redes sociales en un contexto en donde se evidencia la existencia de actitudes racistas y xenófobas. Al respecto se pregunta a un varón trabajador colombiano:

P/ ¿Las bandas juveniles Latinoamericanas son de colombianos?

R/ Ecuatorianos, (Silencio)...dominicanos.

$\mathbf{P} /$ ¿Españoles hay?

R/ También. No Los de "Latin King" (Se refiere a la banda juvenil de los "Latin King").

Son las niñas, que están engañando a las niñas españolas.

P/ ¿Las niñas españolas?

R/ Sí ellos sí, están enredando a las niñas españolas.

$\mathbf{P} /$ ¿Y tú como sabes y tienes esa información?

R/ Por las noticias, y el núcleo que yo he visto, porque aquí en España se ve, aquí...se ve que es un pueblo tan pequeño y se ve, (Silencio) Se ve que hay unos cuatro cinco sinvergüenzas con... que son de "Latín king" que andan con los gorritos, pantalones anchos y todo eso, fumando porros y sin trabajar, unos sinvergüenzas; que sus padres están trabajando y ellos (Silencio) ... paseando y metiendo porro y degenerándose por ahí y dañando a las niñas de aquí también, Tras de que aquí hay mucho vicio, también ellos acaban de dañarlos.

Ahora bien. Cuando la entrevistada es una mujer emigrante trabajadora, tenemos algunas diferencias de apreciación con respecto a la visión de los "otros". Ella pone el acento en el tema de la discriminación racial y en la idea que tienen los españoles sobre la mujer latinoamericana, en particular de las mujeres negras: 
P/ ¿Qué crees que piensan los españoles de los colombianos?

R/ Bueno... yo que te digo hasta... por el color...muchas veces piensan soy negra... y piensan que todas las negras venimos a prostituirnos o que si esta negra la ha tenido que sacar... Yo tengo mi marido, lo hemos vivido y el ha tenido que parar a muchas personas, hacer el reclamo porque dicen... jay de que sitio la sacaste! ¡De qué club la sacaste! Me entiendes, entonces eso es muy triste porque por lo menos yo nunca vine con esa mentalidad y si lo hubiera querido hacer cuando te comenté lo del taxista que me decía mira pues ahí, hay un club, yo tengo muchos amigos, si tú quieres mira a ver, por que se gana más y todo. O sea yo gracias a Dios tengo una familia que me ha criado muy bien, me han enseñado cosas muy buenas, entonces yo pienso que no, no es por esos caminos tampoco y que todas no venimos a prostituirnos y es así, se sienten que están mirando con ese recelo no o si entras algún sitio también, más que todo las mujeres muchas mujeres españolas, se agarran a su marido como diciendo mira... O como si yo se lo fuera a quitar y no es eso (Risas muchas risas).

\section{A MODO DE CONCLUSIÓN}

Podemos establecer que la emigración es un proceso que comienza desde el momento en que el sujeto ha tomado la decisión de emigrar y no sólo desde su llegada al país de acogida. En este proceso, que parte de una toma de decisión personal derivada de múltiples causas: sociales, económicas, personales, no sólo participa el sujeto de la emigración, sino su entorno familiar, sus amigos o aquellas personas que de alguna u otra manera favorecen la toma de decisión.

Iniciada su estancia en el país de acogida, el inmigrante se mueve en dos espacio de tiempo que referencian su vida cotidiana: uno que hemos denominado el "antes": la experiencia de vida anterior a su emigración; y otro, el "ahora", la experiencia de vida actual que se desarrolla en el país de acogida. Estos dos espacios vivenciales marcan y determinan la propia experiencia migratoria; y condicionan la creación de su "memoria migratoria", aquella que las historias de vida se encargan de rastrear e interpretar.

Hay un tercer espacio-tiempo vivencial: el "futuro", es decir, la experiencia que se está construyendo desde el "ahora" y que se convierte en un motor de impulso de la actividad de ese mismo presente, enlazando con el pasado a modo de un "bucle temporal y afectivo". Ese futuro está determinado por un solo objetivo inicial que, en algunos casos y por diversas razones, se irá modificando: volver a su país como un "triunfador".

El "bucle temporal y afectivo" que he mencionado antes, se establece en relación con la "memoria migratoria" que el inmigrante ha realizado a partir de enfrentar su nueva condición social de inmigrante con respecto a su antigua condición en su país de origen. En este sentido, esa idea de futuro se convierte, en el marco de esa "memoria migratoria", en una especie de "redención" entre su pasado y su presente; entre lo que "fue" y lo que "es". En el sentido de ese "futuro redentor" que redime el "antes truncado" por la emigración y el "ahora" como "sacrificio esperanzador". De esta manera, la experiencia migratoria adquiriría toda su expresión como experiencia de vida única, que alecciona y fortalece. Una experiencia de la que al final se espera obtener un "premio". 


\section{BIBLIOGRAFÍA}

BERNÁRDEZ RODAL, A. (dir.) (2007): Mujeres Inmigrantes en España Representaciones en la Información y Percepción Social, Madrid, Fragua.

BINEBINE, M. (2000): La Patera, Madrid, Akal.

BLANCO, C. (2008): "Procesos migratorios contemporáneos y su incidencia en los tradicionales paradigmas de integración" en GARCÍA ROCA, J y LACOMBA, J. (eds.) La inmigración en la sociedad española una radiografía multidisciplinar, Barcelona, Edicions Bellaterra, pp. 267-288.

CALDERÓN, A. (dir.) (2008): $2^{\circ}$ Anuario de la Comunicación del Inmigrante en España 07/08, Madrid, Etnia comunicación, Ministerio de Trabajo y Asuntos Sociales.

CASTELLS, M. (1998): "Paraísos Comunales: identidad y sentido en la sociedad red", en La era de la información económica, sociedad y cultura, Vol. II, Madrid, Alianza Editorial.

CHECA, F. (ed.) (2002): Las migraciones a debate De las teorías a las prácticas sociales, Barcelona, Icaria-Institut Catalá d' Antropología.

GARCÍA ROCA, J. y LACOMBA, J. (eds.) (2008): La inmigración en la sociedad española Una radiografía multidisciplinar, Barcelona, Bellaterra.

LARRAÍN, J. (1996): Modernidad razón e identidad en América Latina, Barcelona, Andrés Bello.

LEWIS, O. (2004): Los hijos de Sánchez Autobiografía de una familia mexicana, México, Joaquín Mortiz. Tratados y manuales Grijalbo.

MARSAL, J. (1972): Hacer la América: Autobiografía de un emigrante, Barcelona, Ariel.

PLUMMER, K. (1989): Los documentos personales Introducción a los problemas y la bibliografía del método humanista, México, Siglo XXI.

RAMÍREZ, E. (1996): Inmigrantes en España: Vidas y experiencias, Madrid, Siglo XXI.

SÁNCHEZ MOLINA, R. (2006): Proceso migratorio de una mujer salvadoreña. El viaje de María Reyes a Washington, Madrid, Centro de Investigaciones Sociológicas.

TORRES, R. (1995): Yo Mohamed. Historias de inmigrantes en un país de emigrantes, Madrid, Temas de Hoy.

THOMAS, W.I. y ZNANIECKI, F. (2006): El campesino polaco en Europa y América, Madrid, Centro de Investigaciones Sociológicas CIS, Boletín Oficial del Estado BOE.

\section{Breve currículo:}

\section{Balvina Rodríguez Benavides}

Licenciada en Ciencias Sociales por la Universidad del Tolima, 2003 (Colombia). Diplomada en Ciencias Sociales por la Universidad Autónoma de Zacatecas, 2004 (México). Ha cursado los cursos de Doctorado en Humanidades y Ciencias Sociales de la Facultad de Filosofía y Letras (2006-2007). Actualmente desarrolla su tesis doctoral bajo la dirección de la Dra. Ana Isabel Blanco García, sobre: Historias de vida e imaginarios sociales de integración de la inmigración colombiana en la España del siglo XXI. Ha trabajado como profesora de la Licenciatura de Sociología (Universidad Autónoma de Tamaulipas, 2008, México). Ha publicado artículos como en la revista: SOCIOTAM. Revista Internacional de Ciencias Sociales y Humanidades. UAT-UNAM (México). Vol. XVII, n.1 EneroJunio 2007: "Hola soy Jairo", pp.141-161. 